\title{
Correction to: Streamflow-based evaluation of climate model sub-selection methods
}

\author{
Jens Kiesel ${ }^{1,2} \cdot$ Philipp Stanzel $^{3} \cdot$ Harald Kling $^{3} \cdot$ Nicola Fohrer $^{2} \cdot$ Sonja C. Jähnig ${ }^{1}$. \\ Ilias Pechlivanidis ${ }^{4}$
}

Published online: 8 December 2021

(C) The Author(s) 2021

\section{Correction to: Climatic Change, 2020, 163, 3, 1267 - 1285 \\ https://doi.org/10.1007/s10584-020-02854-8}

The notation of Regional Climate Models (RCMs) and Global Circulation Models (GCMs) has been mixed-up in the published manuscript and model names and institutes have not been provided in adequate detail. A lookup table is provided below that relates the incorrect GCM and RCM names in Tables 1 and 3 of the published paper to the correct notations.

Consequently, this affects all occurrences of where climate model names are given in the published paper, though model numbers are not affected (pages 1276, 1277 and 1279). In addition, where the performance of the $\operatorname{Div} G$ and DivR sub-selection methods are highlighted, DivG and DivR need to be interchanged. This does not affect the conclusions of the original publication. However, the order of the evaluated performance of the DivG and DivR sub-selection methods requires to be interchanged, where $\operatorname{Div} G$ is correctly ranked $3 r d$ and DivR is ranked $4 t h$.

The online version of the original article can be found at https://doi.org/10.1007/s10584-020-02854-8

\section{Jens Kiesel}

kiesel@igb-berlin.de

1 Leibniz-Institute of Freshwater Ecology and Inland Fisheries, Berlin, Germany

2 Institute for Natural Resource Conservation, Department of Hydrology and Water Resources Management, Christian-Albrechts-University Kiel, Kiel, Germany

3 AFRY Austria GmbH, Hydro Consulting, Vienna, Austria

4 Swedish Meteorological and Hydrological Institute, Norrköping, Sweden 
Correction of GCM and RCM notation

\begin{tabular}{|c|c|c|c|c|c|}
\hline \multicolumn{3}{|c|}{ Notation of models in the published paper } & \multicolumn{3}{|c|}{ Corrected notation of models* } \\
\hline $\mathrm{Nr}$ & GCM & $\mathrm{RCM}$ & $\mathrm{RCM}$ & GCM & RCM Institution \\
\hline 1 & CLMcom-CCLM & CNRM & CCLM4-8-17 & $\begin{array}{l}\text { CERFACS-CNRM- } \\
\text { CM5 }\end{array}$ & CLMcom \\
\hline 2 & CLMcom-CCLM & ICHEC & CCLM4-8-17 & EC-EARTH & CLMcom \\
\hline 3 & CLMcom-CCLM & $\mathrm{MOHC}$ & CCLM4-8-17 & HadGEM2-ES & CLMcom \\
\hline 4 & CLMcom-CCLM & MPI & CCLM4-8-17 & M-MPI-ESM-LR & CLMcom \\
\hline 5 & CNRM-ALADIN & CNRM & ALADIN53 & $\begin{array}{l}\text { CERFACS-CNRM- } \\
\text { CM5 }\end{array}$ & CNRM \\
\hline 6 & DMI-HIRHAM & ICHEC & HIRHAM5 & EC-EARTH & DMI \\
\hline 7 & IPSL-WRF & IPSL & WRF331F & IPSL-CM5A-MR & IPSL \\
\hline 8 & KNMI-RACMO & ICHEC & RACMO22E & EC-EARTH & KNMI \\
\hline 9 & KNMI-RACMO & $\mathrm{MOHC}$ & RACMO22E & HadGEM2-ES & KNMI \\
\hline 10 & MPI-REMO & MPIr1 & REMO2009 & $\begin{array}{l}\text { M-MPI-ESM-LR } \\
\text { r1i1p1 }\end{array}$ & MPI \\
\hline 11 & MPI-REMO & MPIr2 & REMO2009 & $\begin{array}{l}\text { M-MPI-ESM-LR } \\
\text { r2i1p1 }\end{array}$ & MPI \\
\hline 12 & SMHI-RCA & CNRM & RCA4 & $\begin{array}{l}\text { CERFACS-CNRM- } \\
\text { CM5 }\end{array}$ & SMHI \\
\hline 13 & SMHI-RCA & ICHEC & RCA4 & EC-EARTH & SMHI \\
\hline 14 & SMHI-RCA & IPSL & RCA4 & IPSL-CM5A-MR & SMHI \\
\hline 15 & SMHI-RCA & $\mathrm{MOHC}$ & RCA4 & HadGEM2-ES & SMHI \\
\hline 16 & SMHI-RCA & MPI & RCA4 & M-MPI-ESM-LR & SMHI \\
\hline
\end{tabular}

* for the full details, see the CMIP5 webpage: https://pcmdi.llnl.gov/mips/cmip5/availabili ty.html

Publisher's note Springer Nature remains neutral with regard to jurisdictional claims in published maps and institutional affiliations. 